\title{
Analysis on the Development of Small and Medium Sized Enterprises in China's Jilin Province
}

\author{
Zhen-ze Liu, Shu-kuan Zhao \\ School of Management, Jilin University in Chang Chun, China
}

Email address:

zzliu@jlu.edu.cn (Zhen-ze Liu)

\section{To cite this article:}

Zhen-ze Liu, Shu-kuan Zhao. Analysis on the Development of Small and Medium Sized Enterprises in China's Jilin Province. Science Innovation. Vol. 4, No. 2, 2016, pp. 77-82. doi: 10.11648/j.si.20160402.20

Received: March 10, 2016; Accepted: March 19, 2016; Published: April 18, 2016

Abstract: Based on the actual situation of Jilin Province, the current development of small and medium enterprises, the bottleneck problems affecting the industrial environment of small and medium sized enterprises are given and discussed, in addition, the innovation environment of small and medium enterprises in the province is analyzed and the corresponding countermeasures has also been given, finally, the formation path planning of high added value industry of small and medium enterprises in Jilin province is illustrated.

Keywords: Big Data, Industrial Environment Upgrade, High Added Value Foundry

\section{中国吉林省中小企业创新环境发展浅析}

\section{刘振泽, 赵树宽}

中国长春市吉林大学管理学院

邮箱

zzliu@jlu. edu. cn（刘振泽）

摘要：本文基于吉林省当前中小企业升级发展的实际情况，给出并论述了该省影响中小企业产业环境升级的相关瓶颈 问题，对该省中小企业创新环境未来发展模式进行了分析并给出了相应的对策，给出了吉林省产业环境匹配升级下的 相关中小企业高附加值产业形成路径规划。

关键词: 大数据, 产业环境升级、高附加值代工

\section{1. 引言}

中小企业发展对一个国家经济发展至关重要。在美国 [1]，中小企业是美国经济的支柱，中小企业占美国企业 总数的 $99 \%$, 就业人数占私营企业总就业人数的 $50 \%$ 以上, 就业岗位总数占私营企业新增就业岗位的 $65 \%$ 。与大企业 相比, 中小企业出口贸易的趋势也更加明显。在日本 [2], 中小企业的比例相对较高, 在国民经济的作用也比较突 出。日本中小企业是保持经济活力的源泉, 是促进就业的
主力, 是进行技术革命新的中坚力量, 是日本整个国民经 济的基石, 其健康、稳定的发展对日本经济发展具有十分 重要的作用。在欧洲, 中小企业对于欧洲经济更是起到了 举足轻重的作用, 搞好中小企业有利于欧洲整体经济持续 复苏。因此, 研究中国中小企业创新环境的发展意义重大。 本文结合中国吉林省中小企业的发展, 进一步说明了中国 中小企业创新环境的发展势在必行。 


\section{2. 吉林省目前中小企业发展现状}

近年来, 吉林省通过实施民营经济腾飞计划和千户成 长型企业培育计划等一系列重大举措, 极大的促进了当地 的中小企业发展, 繁荣了本地经济, 取得了长足的进展 [3], 但不可否认的是, 吉林省中小企业目前还存在整体 质量不高、能力不强的弊端。

在现有市场激烈竞争形式下, 吉林省中小企业很难迅 速适应发展, 这其中因素众多, 包括文化、体制、历史等, 导致吉林省中小企业发展整体转型升级缓慢。

迄今为止, 我省中小企业多集中在生产低附加值的产 品领域, 主要从事简单加工、粗加工产品方向, 以低端加 工制造业、食品零售业、建筑包装业为主, 主要优势仍集 中于劳动密集型企业。

但随着社会的不断发展与人口红利的逐步消失, 同 时，整个市场原材料价格急速上涨、人工成本增加、人民 币升值, 这导致传统企业发展模式的盈利空间不断减小, 没有核心技术、没有品牌、没有高附加值产品的企业生存 发展的压力越来越大, 加之国家相关政策缺失, 产能过剩 也日益严重 [4]。

但所谓夕阳产业是否一定没有发展前途, 是否单纯的 技术发展就是经济发展的最重要部分, 还值得我们商榷, 例如, 上世纪末, mp3的发展如火如茶, 价格一跌再跌, 门坎一降再降, 技术发展似乎已经走到尽头, 但乔布斯的 思维创新, 使原始的mp 3 被包装上时髦潮流的标签, 一时 风靡世界, 反而成就了苹果多年的发展传奇。触摸屏技术 在上世纪的惠普公司早已问世, 这是在当时看起来没有价 值的技术革新, 而今天看起来这一技术的发展是具有划时 代意义的, 因此是否我们应该转变思路, 不应一昧追求全 新技术, 同时还应对传统技术进行挖掘与改进, 以期将其 应用在最新的领域 [5]。

企业艰难发展的同时, 较重的税费压力更是企业的发 展举步维艰、雪上加霜, 吉林省作为老工业基地的重要分 子, 税务改革缓慢, 严重影响了我省经济发展的速度, 不 仅如此, 国家层面的紧缩性政策导致企业融资困难, 银行 借贷门槛高, 贷款成本的增加也给企业转型升级造成一定 的负担。

除此之外, 政府诚信不足, “开门招商、关门欺商” 问题仍然大量存在, 乱收费、乱推派, 乱指挥的现象屡禁 不止, 优惠政策得不到真正落实, 针对中小企业发展的服 务体系还不健全等。

\section{3. 吉林省中小企业创新环境发展落后的成因}

(1) 我省很多行业领域对中小企业的准入门槛还较 高, 歧视还很严重, 主要表现在对中小企业的发展意识认 识不足, “潜规则” 现象较严重。

（2）我省财税金融支持不足，管制严格，尤其表现 在信贷覆盖率低、实际税负较重、专项财政资金支持少等 方面, 金融机构发展不够健全、创业板市场进入门槛依然 较高、风投公司作用有限的缘故, 金融环境并不能满足省 内中小企业融资需要, 资金缺口较大, 资金来源单一, 银 行贷款难，上市融资条件差，民间借贷费用高昂。
(3) 我省地方管理体系的分散与轻视, 实际工作中 服务意识不强、透明度低、效率不高, 管理、监督过程中, 不能一视同仁, 有时还设置人为障碍, 缺乏高效统一的管 理职能部门, 存在 “多头管理、多头不管” 的现象, 政府 服务于民的意识有待提高, 软环境监管不到位, 缺乏相应 监管体系。

（4）我省在中小企业的私有产权、知识产权界定方 面还存在模糊与薄弱的现象, 导致实际操作的随意性很 大, 侵害问题不可避免, 专利保护仍然不足, 专利费过高, 执法力度弱, 很难有效的保障我省人才发展的刚性需求。

（5）政府对中小企业干预过多，如，对企业直接下 达经济指标、干预企业生产经营、过多地进行评比, 检查 和表彰、组织各项学习活动等。

（6）中小企业本身的治理缺陷是导致中小企业融资 难的直接原因, 确实也发生了一些中小企业虚假注册、捏 造财务数据、逃避银行债务等问题。中小企业的信息不透 明, 法律和有关规则对信息披露没有明确要求, 中小企业 经营者担心社会 “仇富心理” 而不愿披露, 而且即使在披 露的情况下, 企业和银行之间对企业经营本来就存在着信 息不对称。所以在不透明的严重信息不对称的情况下, 银 行的正常贷款行为就必然会考虑到中小企业贷款中存在 的额外风险。

（7）中小企业自身发展潜力不足, 存在设备陈旧, 专业人才缺乏、产品品种单一、技术含量低等问题, 企业 主整体素质不高, 缺乏转型升级意识, 相关能力欠缺 [6]。 由于各种原因, 吉林省目前的中小企业主鱼龙混杂, 整体 素质荝乏, 很多没有经过系统的管理培训, 缺乏管理与沟 通能力, 思想意识相对僵化, 只重视短期利益, 缺乏长远 发展意识, 企业停留在产业层次低的层面上, 挣一笔是一 笔, 缺少长期规划。

（8）吉林省人才培养环境优越，但由于中小企业发 展较弱, 政府管理能力不足, 网络互动环境贫乏, 整体居 住环境恶化, 生活成本过高, 社会软环境恶劣, 导致人才 大量外流。

（9）吉林省中小企业发展模式还较为单一，政府虽 做了大量的引导工作, 但主要还集中在招商引资的思路 上, 导致代工厂的发展模式难以转型, 效果不甚理想, 民 间企业的活力很难激发。银行统筹职能相对薄弱, 比如以 技术和人才为主缺乏抵押物的科技类公司, 很难从银行贷 到款, 银行审批过程繁琐苛刻, 即使企业各项手续齐全, 贷款时间也过长，加大融资成本和难度。

\section{4. 与我省发展情况近似的国外较发达地区或区 域中小企业相关创新环境比较与借鉴 (参照 台湾、香港、新加坡等地区或区域)}

(1) 台湾地区:

1）建立了中小企业的官方辅导机构一中小企业处, 还成立了中小企业的民间辅导机构一中小企业协会和中 小企业开发公司, 为中小企业的快速成长提供了组织保 障; 
2）建立并完善产业导向政策，立法保障政策，金融 扶持政策，人力资源政策和科技服务政策等;

3）采取直接投资、倾向性融资政策、设立科技股和 建立创投基金措施、设立创业育成中心等;

4）对经济的适度干预，遵循综合性、仿效和选择三 原则。

（2）香港地区:

1）积极奉行自由港政策, 自由企业, 自由经营, 自 由投资, 商品进出自由, 货币进出自由, 人员进出自由等 相互联系的六个方面;

2) 积极推行不干预的经济政策，采取低税制、审慎 理财和自由贸易政策等;

3）在推动外来投资和促进生产力发展方面, 推动外 来投资、提供工业用地、鼓励进行应用研究及发展、提供 工业支援服务;

4）在教育投资和技能培训方面，制订政策、加强监 管、提供经费, 资助学费, 设立了雇员再培训局等;

5）积极提供基础设施和公共服务, 设立公司注册处、 土地注册处、技术处理、邮政署、电讯、机电工程等六个 营运资金, 并且与政府账目脱离, 单独核算, 但保留政府 部门和公务员地位;

6）政府扮演公证人角色, 政府与企业隔绝, 企业通 过咨询机构与政府沟通，保证公务员与商界的利益互相隔 绝，同时，双方在咨询方面有着许多沟通;

7）完善的市场体系和市场机制, 产品市场、要素市 场，主要包括金融市场、劳动力市场、房地产市场等;

8）几乎规范一切活动的健全法律;

9）完善和发达的中介组织服务，分布在贸易、金融、 保险、运输、地产和信息服务等各个经济领域。

(3) 新加坡地区:

1）企业层面, 包括提升管理层和员工的素质、推广 最佳管理方式、设计新的经营模式、利用科技和知识促进 增长等四大策略, 目的在于使各企业完成从传统到现代化 经营、从家长到团队式管理、从模仿到创新式运行的转变;

2）行业层面，包括鼓励行业内和行业间的合作与积 极提升服务行业素质两大策略; 宏观经济环境层面, 包括 帮助中小企业融资、市场营销、吸收本地人才、推广电子 商务等多方面的扶持, 目的在于把中小企业在规模上的局 限转化为一种潜力, 确立企业和政府之间的伙伴关系, 将 新加坡发展成区域性中小企业的成长中枢。

3) 建立新加坡标准, 提供技术支持, 在科研机构和 中小企业间架起沟通的桥梁, 帮助企业利用科技改进产品 和服务。鼓励科技创新, 标新局提供技术培训服务, 实行 全套的辅助支持, 鼓励中小企业在开发产品和改进生产工 艺中发挥创意, 研究开发新产品, 不断提高企业的竞争能 力。减低服务费用, 通常比中小企业单独展开项目所需花 费小很多, 大大地减轻了中小企业在资本开销方面的负 担。培育创业人才, 在大学生建立的未来企业家俱乐部里 努力推广创业精神, 培养创业精神, 良好的教育为新加坡 未来中小企业的成长提供了非常稳固的人才基础。加强服 务指导，企业顾问制为中小企业提供咨询指导，为当地企 业提供经营策划、财务管理、市场营销和特许经营等咨询 服务, 协助当地中小企业发展。

\section{5. 吉林省中小企业创新经济环境发展的对策分 析}

吉林省经济发展目前较为塩尤, 在劳务吸引方向, 无 法在工资方面与低收入地区竞争, 因此导致成本与一线城 市相差不大, 无法在尖端技术研制方面与富裕国家地区竞 争, 虽然我省有著名的动漫基地, 但与发达地区相比, 仍 然无法主导市场, 虽然我省是著名的汽车大省, 但近年来 不断发展的上海汽车, 广州本田, 深圳比亚迪等企业都对 我省的汽车发展形成了威胁与挑战, 吉林省目前的龙头企 业较少, 像修正药业、皓月集团这样的企业风毛菱角, 但 同比弹丸之地的台湾省, 却出现了恒基、华硕等一大批发 展企业, 这主要彰显在台湾省电子工业的定位。

虽然有种种不利的条件存在，但吉林省在人才教育、 科技和资本形成等方面优势凸显, 人才教育方面, 吉林省 是当之无愧的人才大省, 高校密集, 师资雄厚; 科技发展 方面, 光学基地, 药学基地林立; 资本形成方面, 老工业 基地发展政策支持，民间储蓄资本雄厚。

而上述这三点正是产业升级的核心竞争力, 因此, 吉 林省的发展应该更上一层楼, 如果能发挥我省自身优势积 极完成中小企业创新环境的优化, 做一场适合本省实际情 况的 “产业升级” ，则吉林省的发展大有可为。

(1) 加大基础设施建设, 主要表现在

1）免费网络的分布，如果我省能打造全国第一个省 内无障碍免费无线上网的区域品牌, 保证处处有wifi, 时 时有免费, 则可以花小钱办大事, 极大的吸引年轻劳动力 在我省谋发展;

2）人文细节关怀的设置，我省的公共汽车可以进行 无障碍设计, 在车辆进站时, 汽车可以借助液压传动技术 自动升降, 从而帮助残疾人、老年人等弱势群体乘车, 这 一群体的质量提升将从侧面有助于诸多科技人员在工作 地点选择考量, 如果我省能在无障碍通道这一方向做大文 章, 包括楼宇、商厦、街路等, 将会大大提升我省在全国 的品牌树立, 能起到事半功倍的作用;

3）加大省内社区服务基础建设, 集中精力建设社区 图书馆、城市图书馆、省级图书馆, 建设的重点在于精简 图书的还借程序, 建立多渠道的图书阅读通道, 设计合理 便捷的图书摆放通道, 把图书机构建设成休闲、休息、休 假的去处, 吸引各层次人群理性回归。

4）在条件允许的情况下, 积极修建各类高楼层停车 场, 逐步减少城市停车难、乱、差的现状, 节约用地, 缓 解紧张, 并且可以对相关繁荣区域进行二次理性规划, 变 求大、求全、求多为求精、求小、求简。

5) 完善省内公共场所的服务措施, 诸如设计劦婴专 用洗手间, 贞儿喂奶室, 儿童娱乐室等, 无障碍通行车等, 将商业运作与公益设置进行有机的结合。

关于基础设施的建设是个艰巨而宏大的工作，这种基 础建设不应局限在政绩工程的追求, 更应踏踏实实地做好 细枝末节的关怀工作，这些工作的不断完善对于整个区域 的软环境有根本的促进作用, 将建立良好的吸引效应, 对 于人才的流动有着巨大的作用, 对于企业的发展有积极的 促进, 对于整个区域的政治生态、经济生态、人文生态有 着至关重要的作用。 
（2）加大并完善发达的中介组织服务

一直以来, 我们对中介组织服务的积极作用有所局 限, 应积极突破, 要鼓励多种中介组织存在, 这些中介组 织要分布在贸易、金融、保险、运输、地产和信息服务等 各个经济领域，为当地和境外的投资者、经营者和消费者 提供各种中介及信息咨询服务, 真正使中介机构成为沟通 政府和中小企业、交易双方不可缺少的桥梁。同时，政府 应加强监督并法定公营机构, 鼓励各类商会, 完善企业制 度, 在法律上明确中小企业的公司治理结构和地位; 强化 行业协会、自愿性组织及公众对中小企业治理机制的监 督; 强化对各类股东、债权人及其他利益相关者的权利的 保护; 向社会公开企业登记注册和税收等信息并制度化, 建立适合于中小企业的财务制度、会计制度和审计制度; 积极发挥风险投资等机构投资者的作用。鼓励服务范围很 广的中介服务公司，包括产品推广、金融、投资、企业管 理、资信调查等, 鼓励专业服务机构, 包括律师会, 会计 师公会, 测量师学会及大量的律师行、会计师行及测量师 行等, 主要集中在以下服务方向:

1）法律服务，范围涉及公司商务，银行业务和财务 等各个领域, 包括资本市场交易、项目融资、债务问题、 银行证券、担保、贷款及其他融资、设备租赁和分期付款, 与公司财务活动相关的交易等。证券方面, 包括首次公开 发售, 发行股票、债券、衍生工具等。产权转让方面, 包 括物业开发、融资、业主与承租人协议、物业评价及安全 强制措施, 商业与住宅楼宇出售和购置等。知识产权方面, 就知识产权的权益, 如所有权保护、转让、许可证等提供 建议。诉讼和仲裁方面, 法院处理所涉及的仲裁及诉讼和 纠纷。其他方面还包括家庭、环保、保险、税收、广播及 媒体等。

2) 会计服务，执业会计师行主要提供法定核数、税 务顾问、公司上市、公司融资、公司秘书、公司清盘及审 计调查等服务。在一般情况下, 执业会计师行向顾客提供 全面的商业会计服务。非执业会计师行只提供簿记、一般 会计服务、年终财务报告、税务归档和公司秘书工作。

3) 测量与估值服务 [7] (1)物业估价。主要包括评估各 类物业出租、转让及按揭等的价值, 提供与收地赔偿、租 务管制、差饷、厘印税及遗产税等有关的物业估价服务; 评估公司的物业价值，为公司上市、收购、合并及估量资 产服务; 在有关物业价值的纠纷或诉讼中, 以独立估价师、 仲裁人或专家身份提供专业意见。(2)工业发展顾问。主要 服务包括: 对各种发展计划的可行性做出分析评估及市场 研究, 与政府洽商有关修改地契的细则, 土地收回及重批 等事宜, 就更改土地用途等问题向城市设计委员会提出申 请, 制定发展规划及设计大纲, 在发展过程中就财政安排 做出详细估计，并分析资金流动情况，管理工程开支等。 (3)土地及楼宇租售。测量师代表客户洽商收购及租售各类 土地及楼宇, 主持物业拍卖, 并为业主以招标方式出售或 出租物业, 为客户提供市场推广策略, 就有关物业租售的 法律文件细则提供建议。(4)物业管理。测量师负责各类楼 宇的管理, 并代客户洽商有关租金调整、续约及楼宇租用 等事宜。
4) 商业顾问服务, (1)一般管理。包括公司及业务策略、 机构重组和改造管理; (2)财务管理。包括资本投资方案的 分析、会计及预算控制系统的开发和业务评估等; (3)营销 管理。包括营销策略的形成、顾客服务和定价原则等; (4) 生产管理。包括增产曲线研究、材料规划、生产资源规划、 适时生产等; (5)力资源管理。包括薪酬调查、工作评估、 工资比率测算、职务管理和培训等; 6信息技术管理。包 括策略研究和系统开发等。

（3）鼓励并改革省内相关金融机构的审批及发放程 序

具体做法为鼓励地区银行等金融机构改革相关的贷 款审批程序、改革中小企业授信制度、探索实行最高限额 抵押贷款管理办法、改进信贷考核体系、适度改革存贷比 例管理方法。中小企业数量多、规模和形式千差万别, 要 推进金融体制改革, 设立适合不同中小企业贷款的金融服 务尤为重要, 可以从以下几个方面来实现。

1) 建立多元化金融服务体系。对于那些发展前景好、 盈利能力强的企业, 银行可以酷情增加对其的信贷投入; 银行应该加大对中小企业重视程度, 增加产品种类, 向中 小企业倾斜; 注重建立中小企业信用档案, 完善中小企业 信用评级制度, 提高企业信用意识, 加快银行贷款的审批 程序。

2) 加强对中小企业担保机构政策上扶持。政府要加 大对一些信誉好、管理规范的担保机构的资金投入，增强 他们的实力。要完善风险分散机制, 通过建立贷款风险补 偿基金，对所发生的风险损失给予一定比例的补贴，对于 一些业绩不错的、对于中小企业贷款做出贡献的担保机 构, 政府可以考虑给予奖励; 政府也可以出资成立政策性 担保机构。

3）利用现有大量的民间资本，鼓励发展中小型民营 银行、地方银行。有关部门可以扩大现有村镇地区银行试 点范围, 进一步放宽在金融市场中准入、规模、利率浮动 幅度等方面限制, 引导资本步入正常资本市场。

4）. 建立专门为中小企业服务的银行, 满足中小企业 的发展模式。

5）政府要积极促进推动中小企业直接融资 [8]，创造 条件推动企业上市。确定可培养上市企业对象, 通过降低 赋税、奖励上市、政府采购等手段来推动中小企业上市, 逐步建立长效管理机制, 对中小企业上市培育工程要真抓 实干, 对于有意愿有能力的企业指导上市, 并且给予一定 的资金支持和技术指导来鼓励上市。

（4）在国家整体法律的框架下, 规范地方活动的健 全法律与条例

例如，在规范工商业方面，即有规范公司及其他经济 组织的条例, 如公司条例、破产法、银行业条例、接受存 款公司条例、地下铁路公司条例、机场管理局条例等。又 有规范公司及各类经济组织经营及交易行为的条例, 如票 据条例、商品贸易条例、纳税条例、货物代理商条例、证 券条例、进出口条例、股票交易条例、劳工条例、雇佣条 例等, 这些严密的法规条例, 使得省内从事任何经济活动, 都可以找到法律的依据并受到法律的监督。同时要营造一 个安全健康的法制环境, 对于中小企业在法律方面的问 
题, 政府要积极提供法律援助, 合理正确的保护中小企业 的权益、保证中小企业的资产不受侵犯, 生产经营活动得 以正常顺利进行。继续对民营中小企业实施减税政策。

（5）引导民营中小企业提高自主研发能力

经过调查发现, 在500强的民营企业中约有350家自主 研发关键技术，这说明未来企业发展趋势已经逐渐脱离 “制造” 而走向 “创造” 的道理, 要改变过去单纯依靠引 进技术为主, 改为自主创新为主的新模式, 这种自主创新 不仅仅应该是技术上的, 更应该是思维思考的一种风尚的 引领, 这也正是目前的中小企业发展的最佳模式。要全面 提升中小企业自身素质，不断地提升信息化水平，增加企 业信息透明度、加大人才和科研投入力度、明晰企业产权, 建立股份合作制、规范完善财务制度，提高财务管理水平、 加强企业自身管理, 提升企业的信用等级、积极寻找新的 融资渠道等方式。

\section{6. 有关吉林省中小企业创新经济环境发展的相 关思考}

建立我省中小企业发展详尽规划设计, 主要表现在

（1）对目前国际范围内先进行业进行详尽调研, 在 过去引进先进技术、引进生产制造、引进科研成果的基础 上, 设立代工策略, 尤其针对低附加值的传统劳动产业与 污染密集型产业进行分析

例如, 我省动漫产业 [9]较为发达, 但缺乏市场定位, 很难打出自己的品牌, 因此与日本等发达国家或地区很难 竞争, 如何走出自己的品牌之路, 脱离单纯为其他机构培 养人才、为他人作嫁衣的尴䂓局面。日本的动漫产业定位 为全民动漫, 大量出口, 主打励志、情感牌, 因此, 吉林 省应积极鼓励反应传统中国文化的动漫产业化, 这是中国 的特色，激励鼓励创作吉林省区域民间传说、民间文化、 地方历史人物、地区特色的动漫产业化，这是吉林省的特 色, 政府应制定相关措施, 刺激相关群体注册相关中小企 业, 从事相关活动, 营造动漫产业化氛围。

再比如, 吉林省是汽车大省, 以往, 我们过度重视新 车、新技术的引进, 事实上, 长此以往, 我们很难实现自 主创新。应积极考虑, 在整车正常发展的前提下, 对相关 产品进行标准化, 化整为零。例如, 汽车刹车片, 如果我 们能够对众多品牌汽车刹车片进行整体分析, 找出其共同 点与相异处, 做出自己标准的刹车片, 从而成为各个品牌 汽车的高级代工工厂。

通俗的讲, 比如比亚迪自己生产刹车片, 宝马自己生 产刹车片, 大众自己生产刹车片, 需要投入大量的人力物 力, 但各个汽车厂商生产的刹车片标准又不尽相同, 如果 能做出一个相对标准, 使得几个不同品牌厂商只需经过简 单处理就可以达到各自品牌的要求, 则可以大大降低成 本, 不仅如此, 这种代工工厂不同于以往单纯的低层次代 工，而是高层次的代工，是行业新的标准制定者。

（2）结合我省教育优势，依托当地的中小企业服务 局, 联合知名教育机构, 组织知名教师和学者对企业领导 人和管理人员进行相关管理培训, 提高管理人员的管理能 力, 这种组织不能作为单纯的政府行为, 否则, 不但会跟
政府造成负担, 同时难以激发企业和教学机构的热情, 需 要借助市场经济的杜杆进行调节, 既让教育机构感觉到市 场前景大有可为, 同时也让企业感觉到教育确实给企业带 来了收益, 让企业与教育机构双向选择, 真正实现互惠互 利双赢的局面。

（3）建议创立政府创业投资引导基金，主要集中资 助极具创新思想的民间创意企业, 不求立竿见影, 但求引 导思维。引导对地方商业银行的小企业贷款设立风险补偿 基金、对民间资本进行积极有效的引导与规范、企业组成 联合担保组联合贷款、允许进行股权质押贷款等方法, 适 当下放审批权限，建设 “绿色通道”、实现专业担保公司 与金融机构合作，共同分担风险、为企业提供差异化服务 等方法; 借鉴新加坡科学拟定中长期发展规划、开展融资 援助计划、资产证券化融资、建立风险投资融资体系等方 法。

（4）在政府职能的权限范围内, 完善并积极鼓励中 小企业接触金融市场 [10], 包括银行同业市场、外汇市场、 证券市场、银团贷款市场、资本市场、黄金市场、保险市 场以及衍生金融工具市场、期货市场等，积极开拓国际性 服务市场, 包括对外贸易、批发、仓储、零售、运输、饮 食、酒店、旅游、文化、房地产、通讯、财务、保险、金 融等各方面, 充分发挥政府职能, 协调并建立适应我省发 展的市场机制, 主要包括利益导向机制、竞争机制、供求 机制、价格机制等, 加强对外开放程度, 减少政府干预度, 提高竞争程度, 加强对外应变能力。据研究表明, 目前中 国整体债券市场弱小, 我省的市场就更为弱小, 特别是公 司债, 其发行规模更小, 尚未成为企业融资的常规渠道之 一。因此有必要发展多层次的市场化融资渠道, 促进金融 市场的竞争, 尤其要加快企业债券市场的发展, 建立适合 中小企业股权融资市场。建立和完善企业征信制度。鉴于 社会征信体系建设需要协调各个地区政府、各类机构、银 行和企业的利益以及征信体系具有投资巨大的特点, 由中 央政府进行推动甚至直接组织是有必要的, 同时还有必要 建立征信和信用管理方面的法律法规。促进中小企业融资 创新, 鼓励中小企业采取融资租赁、担保、保险等融资方 式, 同时解决相关的法律和制度障碍。放松金融管制，允 许私人资本市场的形成, 鼓励私募融资方式的发展. 放松 对私人资本进入金融服务业的限制。

\section{7. 结论}

有关中小企业创新环境问题的解决是一个任重而远 的使命, 需要企业、社会、政府、公众的共同努力, 需要 建立起中小企业的信用体系, 从而不断满足中小企业进入 资本市场直接融资的需求。需要完善中小企业信用担保体 系, 加强信用担保方面的政策法规建设、健全担保资本金 注入机制、加快发展民营担保机构, 鼓励民营资本开办商 业性互助投资担保机构，支持同行业企业联合出资成立共 同担保公司、完善担保机构税收优惠政策、重点扶持担保 机构、推进金融部门与担保机构的互利合作、加强对担保 机构的监管与指导。需要加大政府对中小企业融资的扶持 力度。在可能的范围内, 尽量放宽非公有制企业的进入门 槛、依法塑造中小企业公平竞争环境、依法制定优惠政策、 
推动中小企业直接上市、建立壮大企业互助融资担保机 制, 需要政府加大对企业技术创新的扶持力度, 通过 “政 府采购”、担保贷款等方式支持企业技术创新，企业借助 政府扶持政策，加快技术更新速度、提升产品的技术含量 和新产品换代, 使得企业具备更强的抵御风险的能力。需 要政府积极引导中小企业调整发展策略, 调整自身产业结 构、创新企业运营模式、向新兴产业和现代服务业发展, 不断提高企业的竞争力。需要政府要积极推进电子商务平 台建设, 搭建一个为企业增加出口和内销的平台帮助中小 企业渡过难关。

\section{参考文献}

［1］郑伟, 美国中小企业研究现状 (上) [J]. 首席财务官, 2014 (11X)。

[2] 高文文, 日本中小企业的信息化及对我国的启示 $[J]$. 边疆 经济与文化, 2014(10)。
［3］曹阳、任玉珑，创业支撑体系建设的实证分析 [J]，重庆大 学学报 (自然科学版), 2006 (09)。

[4] 于珍, 产业集聚与技术创新的关系分析 [D], 山东大学, 2007 。

[5] 余芳珍, 提升自主创新能力的开放式创新源管理 [A], 第三 届科技政策与管理学术研讨会暨第二届科教发展战略论坛 论文汇编 [C], 2007。

６］李俊江、范思琦, 从封闭走向开放一日本中小企业创新模 式的转变, $[\mathrm{J}]$, 东北亚论坛, 2010（05）。

[7］毕克新、王䈶、高巍, 基于VIKOR法的科技型中小企业自主 创新能力评价研究 $[J]$ ，科技进步与对策2011（01）。

[8] 陈艳, 金融危机背景下我国中小企业融资问题的实证研究 $[\mathrm{J}]$, 东北财经大学学报, 2011 (03)。

[9] 栾明, 吉林省动漫产业发展及其路径研究 $[J]$ 。企业经济, 2014, 3: 026。

[10］周德才、何宜庆、卢晓勇等。中国金融市场动态相关性实 证分析 $[\mathrm{J}]$, 统计与决策, 2015 (1) : 110-114。 